\title{
MÍDIAS E CULTURAS POPULARES CONTEMPORÂNEAS: MEDIAÇÃO E TUTELA
}

\author{
Contemporary media and popular culture: mediation and protection
}

Medios en la contemporáneidad y la cultura popular: meidación y tutela

Maria Salett Tauk Santos ${ }^{1}$

\begin{abstract}
Resumo
O texto analisa a relação que se estabelece entre a mídia massiva e as culturas populares contemporâneas, no cenário de enfrentamento da desigualdade social e de construção da cidadania. A partir da análise de mensagens veiculadas pelo jornalismo impresso e audiovisual no Brasil, a pesquisa demonstra o papel tutelador assumido por essas mídias quando a audiência envolve populações de contextos populares. Assim, muda o sentido da comunicação entre a mídia e seus receptores. No lugar de falar para ou com as audiências populares, a mídia fala por elas ou em nome delas.
\end{abstract}

Palavras-chave: mídia, culturas populares e cidadania.

\begin{abstract}
The article analyse the relationship between mass media and contemporary popular culture in the context of social inequality and citizenship building. From the study about the messages conveyed by print journalism and audiovisual in Brazil, the research demonstrates the tutelary role assumed by these media when the audience involves popular contexts. So, change the meaning of communication between the media and their receptors. Instead of talking to or with popular audiences, the media speaks for them or on their behalf.
\end{abstract}

Keywords: media, popular culture and citizenship.

\section{Resumen}

El texto analiza la relación que se establece entre los medios de comunicación masiva y las culturas populares contemporáneas, en el escenario de enfrentamiento de la desigualdad social y de la construcción de la ciudadanía. A partir del análisis de las mensajes difundidas por el

\footnotetext{
${ }^{1}$ Maria Salett Tauk Santos - Jornalista, Doutora em Ciências da Comunicação pela ECA-USP. Professora do Programa de Pós-Graduação em Extensão Rural e Desenvolvimento Local (Posmex) da Universidade Federal Rural de Pernambuco - UFRPE; Coordenadora do GP Comunicação e Desenvolvimento Regional e Local da Sociedade Brasileira de Estudos Interdisciplinares da Comunicação - Intercom E-mail: mstauk@ hotmail.com, Tel. (55-81) 8812-8500.
} 
Mídias e culturas populares contemporâneas: mediação e tutela

de Maria Salett Tauk Santos

periodismo impreso y audiovisual en Brasil, la investigación demuestra el papel de tutor asumido por esos medios cuando la audiencia adviene de contextos populares. Así, cambia el sentido de la comunicación entre los medios de comunicación y sus receptores. Al revés de hablar para o con las audiencias populares, los medios hablan por ellas o en nombre de ellas.

Palabras-clave: media, culturas populares y ciudadanía.

\section{INTRODUÇÃO}

O objetivo deste texto é analisar a relação que se estabelece entre a mídia massiva e as culturas populares contemporâneas, no cenário político de enfrentamento da desigualdade e no espaço de construção da cidadania. Trata-se especificamente de compreender o sentido contemporâneo das mediações exercidas pelos meios de comunicação, quando as audiências são as culturas populares.

A realidade do mundo contemporâneo está cada vez mais complexa. Para Morin (1998) essa complexidade se apresenta como dificuldade, como incerteza e nunca como clareza e como resposta às inquietações presentes. A sociedade vive hoje, como assinala Martin-Barbero, um momento no qual o conhecimento oscila num movimento de certezas e incertezas. E essas incertezas se vêem hoje atravessadas pelo medo. Para o autor estamos vivendo uma volta ao medo dos pré-modernos, o medo da natureza, da insegurança. Os principais vetores dessa incerteza vêm da ecologia, no sentido da incerteza sobre o que vai acontecer com o planeta; a violência urbana; e o mundo do trabalho, por ter se descaracterizado como espaço de produção do sentido da vida. A consequiência desse cenário na vida cotidiana é que "continuamos dependendo de mediações para dar conta da complexidade do mundo, seja a mediação de partidos políticos, de associações de cidadãos" (MARTIN-BARBERO 2008: 12).

$\mathrm{Na}$ lista de mediadores, os meios de comunicação desempenham um papel fundamental em razão de ter entre as suas funções mais importantes não apenas reportar, mas a de interpretar para os cidadãos a realidade complexa da sociedade contemporânea, que perdeu o sentido comunitário. A ação dos mediadores torna-se, portanto, fundamental nessa sociedade, como explica Martin-Barbero, na medida em que nela romperam-se os laços de organicidade, existentes nas comunidades prémodernas, onde haveria muitas ligações religiosas, laborais, entre seus membros. A centralidade que ocupam hoje os meios de comunicação resulta, como assinala o autor, 
desproporcionada e paradoxal em países como o nosso, “com necessidades básicas insatisfeitas no âmbito da educação ou da saúde, onde o crescimento da desigualdade otimiza nossas sociedades, deteriorando os dispositivos de comunicação, isto é, de coesão política e cultural”. (MARTIN-BARBERO, 1998: 12)

Nesse cenário político, o papel mediador dos meios foi reconfigurado no sentido de que a mediação televisiva e das chamadas mídias sociais, passou "a fazer a parte da trama dos discursos e da própria ação política” (MARTIN-BARBERO 1998: 14). Essa mediação que o autor considera "socialmente produtiva" na medida em que a mídia não se limita a veicular as representações existentes, mas passa a "constituir uma cena fundamental da vida pública. E o faz reintroduzindo, no âmbito da racionalidade formal as mediações da sensibilidade" (MARTIN-BARBERO 1998: 14). Nesse esforço a ação mediadora da mídia possibilita não apenas "invadir o espaço doméstico como também reintroduzir em seu discurso a corporeidade, a gestualidade, isto é, a materialidade significante de que se constitui a interação social cotidiana". (Martin-Barbero, 1998: 14).

Pensar a política a partir da mediação dos meios é vital, pelo menos em dois sentidos. Primeiro, não se pode pensar a democracia participativa fora da cena pública erigida pela comunicação massiva; segundo, o exercício da política no campo simbólico que os meios possibilitam, fortalece nos cidadãos o sentimento de pertencer a uma comunidade (MARTIN-BARBERO 1998).

No campo da ação mediadora da mídia massiva em relação às culturas populares observa-se, entretanto, um fenômeno cada vez mais frequente que consiste em os meios saírem da condição de mediadores/interpretes das práticas sociais, para assumirem o papel de mediadores/protagonistas dos processos políticos que envolvem essas culturas.

Nessa perspectiva, a mediação dos meios de comunicação de massa que possibilitou a emergência do popular massivo, como podemos observar através do depoimento do artista popular, Mestre Salu:

Por que Salustiano tem essa mídia hoje? Porque Salustiano viajou prá Cuba, prá São Paulo, Belo Horizonte, Rio, Rio Grande do Sul, Curitiba, Natal, Fortaleza, Bahia. Toquei em Salvador e foi um sucesso... a gente chegou lá com o Maracatu no Sonho da Rabeca e a gente botou moral no Pelourinho, o pau cantou, foi um público satisfatório mesmo. Tinha gente até que já me conhecia, veja onde chega a história do artista. Agora, enquanto você não vai pra fora, não pega mídia, não. Esse público que vem pras apresentações são os universitários... porque chegou meu conhecimento na mídia da revista, da televisão, do rádio, dos jornais, aí eles ficam empolgados. Porque o artista quando ele pega brilho, aí o povo começa a procurar. Quando ele não tem a 
mídia, faz como no interior, que a nossa mídia lá era o boca a boca. (Mestre Salu, apud TAUK SANTOS 2001: 264).

Favoreceu o desenvolvimento de um outro fenômeno, disseminado nos meios de comunicação de massa, que consiste na mídia sair de sua condição de mediadora para a condição de protagonismo e tutela dos processos sociais e políticos, que envolvem as culturas populares. Essa prática tem como conseqüência a mudança no sentido do contrato de comunicação que segundo Eliseu VERÓN (1983) se estabelece entre a mídia e seus receptores. No lugar de falar para as audiências populares, a mídia fala por elas ou em nome delas.

\section{A PESQUISA: MEDIAÇÕES CULTURAIS COMO ABORDAGEM TEÓRICO-METODOLÓGICA}

A mediação para Martin-Barbero é o lugar de produção de sentido da comunicação. O autor privilegia a cultura como a mediação fundamental de todos os processos sociais e afirma que "das mediações há que se partir para as práticas sociais, práticas entendidas como processo de ação social dos sujeitos" (MARTIN-BARBERO apud OROZCO GOMEZ 1997: 115).

Para Orozco (1997) o que é importante compreender sobre o uso do modelo das mediações, proposto por Martin-Barbero, é que não existe uma relação direta entre os componentes do processo da comunicação (emissor, meio, mensagem, receptor). Nesse processo "nada está conectado diretamente com nada, senão que há uma série de mediações que incidem e conformam a interação entre um e outro dos componentes" (OROZCO GOMEZ 1997: 114). Na compreensão de Martin-Barbero as mediações se manifestam em práticas concretas. Ele salienta três que considera particularmente importantes para compreender a comunicação e a cultura: a sociabilidade, que diz respeito às práticas cotidianas de todos os sujeitos sociais na negociação do espaço uns com os outros; a ritualidade, relacionada às rotinas, que determinam de certa maneira a produção de sentido e a produção cultural que se dá através delas; e a tecnicidade, que tem como referência as tecnologias da informação e da comunicação, âmbito de onde se manifestam as mediações culturais.

$\mathrm{Na}$ perspectiva de operacionalizar as mediações propostas por Martin-Barbero, Orozco Gomez propõe o modelo das mediações múltiplas, que passa necessariamente 
por um enfoque integral da recepção, considerando-a como um processo complexo, multidimensional e multidirecional que sofre a intervenção do contexto cultural, político e histórico (OROZCO GOMEZ 1997). Ele classifica as mediações em cinco fontes fundamentais: individuais ou cognoscitivas, que provém da nossa individualidade enquanto sujeitos sociais, membros de uma cultura; institucionais, se manifestam a partir da participação do indivíduo nas instituições como a família, a escola, a igreja, o trabalho; mediações situacionais, relacionadas com a situação em que a recepção se processa; mediações de referência, que incluem as características inseridas num contexto determinado como idade, sexo, ocupação; e as mediações mass mediáticas ou videotecnológicas, que emanam da tecnologia, do meio de comunicação, envolvendo a intencionalidade do emissor (OROZCO GOMEZ apud TAUK SANTOS 2006).

Há que se considerar, como afirma Tauk Santos (2006) que as mediações não constituem balizas prontas das quais o pesquisador se apropria para explicação de um determinado fenômeno na audiência. Trata-se, antes, de uma construção metodológica a partir da qual o próprio objeto de estudo é quem revela ao pesquisador a mediação ou mediações principais, intervenientes em cada processo de comunicação, que a autora denomina mediações “por excelência” (TAUK SANTOS, 2006: 105)

É na perspectiva teórica das mediações culturais que foi construída a metodologia deste estudo a partir da mediação tecnológica cotejando o caráter de protagonismo político e de tutela exercido pela mídia, em processos de comunicação onde os receptores são as culturas populares.

O popular não deve por nós ser apontado como um conjunto de objetos (peças de artesanato ou danças indígenas), mas sim como uma posição e uma prática. Ele não pode ser fixado num tipo particular de produtos e mensagens, porque o sentido de ambos é constantemente alterado pelos conflitos sociais. Nenhum objeto tem o seu caráter popular garantido para sempre porque foi produzido pelo povo ou porque o povo consome com avidez; o sentido e o valor populares vão sendo conquistados nas relações sociais. É o uso e não a origem, a posição e a capacidade de suscitar práticas ou representações populares, que confere essa identidade. (GARCIA CANCLINI 1983: 135).

É dessa relação que emerge a condição de desigualdade a que se acha submetido o popular em relação ao conjunto de sociedade:

As culturas populares existem porque a reprodução desigual da sociedade gera uma apropriação desigual dos bens econômicos e culturais por parte de diferentes classes e grupos na produção e no consumo; uma elaboração própria de suas condições de vida 
e uma necessidade nos setores excluídos da participação plena no produto social; (GARCIA CANCLINI 1987: 49).

Nessa perspectiva os contextos populares devem se compreendidos como cenários onde predominam populações que vivem em condições desfavoráveis e se desigualdades dos pontos de vista social, político, e econômico, em relação ao acesso e apropriação dos produtos de riqueza do mundo. (TAUK SANTOS, 2009).

As interações comunicacionais que se estabelecem entre a cultura de massa e o popular favoreceram a abordagem teórica que considera as culturas populares em processo de hibridização com a cultura massiva, como assinala Garcia Canclini “o popular não aparece mais como oposto ao massivo mas como um modo de atuar nele" (CANCLINI 1987: 49). Processo que se intensifica com o advento das redes tecnológicas e sociais, presentes no cotidiano das culturas populares e que ampliam e dão maior visibilidade à dinâmica de negociação de sentidos e u sos de bens materiais e culturais, na disputa entre hegemonia e contra- hegemonia, como assinala MartinBarbero:

Estamos diante de uma profunda reconfiguração das culturas - camponesas, indígenas, negras -, que responde não somente à evolução dos dispositivos de dominação, mas também a intensificação de sua comunicação com as outras culturas de cada país e mundo. No interior das comunidades, esses processos de comunicação são percebidos ao mesmo tempo como outra forma de ameaça à sobrevivência de suas culturas e como uma possibilidade de romper a exclusão, como experiência de interação que comporta risco, também abre novas figuras de futuro, pois há nessas comunidades menos complacência nostálgica para com as tradições e maior consciência da indispensável reelaboração simbólica que exige a construção do futuro. (MARTIN-B ARBERO 2003: 64-65)

Com base em estudos empíricos que envolvem a relação da mídia massiva e as culturas populares e tomando como perspectiva de análise a mediação protagonismo da mídia analisaremos como, a despeito da compreensão teórica de que o popular é constitutivo da cultura de massa, a mídia tende a desenvolver uma posição de tutela frente a essas culturas.

A pesquisa utilizou técnicas combinadas de coleta e análise de dados o corpus empírico da análise foi composto de duas reportagens da série "Vida Real" da Rede Globo de Televisão no período de outubro a de dezembro de 2009; entrevistas com editores e repórteres do Jornal diário Folha de Pernambuco a partir de roteiro de entrevista semi-estruturada; além de dados secundários obtidos de uma pesquisa com 
Mídias e culturas populares contemporâneas: mediação e tutela

de Maria Salett Tauk Santos

jornalistas, editores e repórteres do programa jornalísticos NE TV $1^{\text {a }}$ edição, considerado pela emissora como um telejornal comunitário.

\section{PROTAGONISMO E TUTELA}

A Folha de Pernambuco, jornal diário criado há 10 anos, é um exemplo pertinente do que significa um projeto, que do ponto de vista mercadológico, gráfico e editorial, foi concebido para falar com os contextos populares e em nome deles. Um jornal afinado com o gosto popular a partir da sua feição gráfica. O ponto de partida foi o projeto gráfico que optou pela utilização do amarelo e do preto, sob a alegação de que a vida do povo é colorida, como afirma Adriana Coutinho ex-editora de arte da Folha de Pernambuco:

O Jornal apresenta cores fortes, vibrantes como em todas as manifestações de arte da cultura popular pernambucana: maracatu, frevo, côco. Nos pratos da culinária, nas paisagens litorâneas e áridas do sertão. (COUTINHO apud TAUK SANTOS, 2000: 9).

A proposta editorial voltada aos contextos populares, explica a ex-editora geral da Folha Paula Louzada, deve-se à constatação de que é escasso o noticiário sobre essas populações "a Folha veio para mostrar o que essas pessoas estão vivendo no bairro delas" (LOUZADA, apud TAUK SANTOS, 2000: 10).

Como parte dessas estratégias a Folha adotou o uso da linguagem próxima da linguagem popular:

Os títulos são feitos sem verbo, para dar mais força as manchetes: "crime barato", "real despenca", "cuidado com seu bolso". (LOUZADA apud TAUK SANTOS, 2000:10).

Cotejando as temáticas de interesse popular:

[...] em economia a gente privilegia a questão do consumidor, como a questão do aumento do crediário. (LUIZ HERRISON apud TAUK SANTOS, 2000: 10).

[...] um artigo sobre política do estado, a folha faz logo uma abordagem sobre o vilão da situação que é o desprego". (LOUZADA apud TAUK SANTOS: 11).

E assumindo o protagonismo e a tulela em defesa da população dos contextos populares: 
Toda manha tem um repórter nas comunidades. Vão atender aos chamados pela central de atendimento: cano estourado, buraco na rua falta de iluminação, a gente bota a boca no mundo. (LOUZADA apud TAUK SANTOS, 2000: 11).

A Folha é assim um intermediador, por exemplo: as pessoas fazem um trabalho de esporte na comunidade, mas o problema é arrumar patrocinador. A gente divulga o que é um trabalho serio, a empresa patrocinadora vai atrás (BETO LAGO apud TAUK SANTOS 2000: 11).

No estudo intitulado Comunidades midiáticas e culturas: as interrelações dialógicas na produção dos telejornais da Globo NE e Jornal do almoço, a autora ${ }^{2}$ traz depoimentos de jornalistas, editores e repórteres do NE TV, primeira edição, considerado pela emissora como jornal comunitário. Nas falas dos entrevistados o sentido de comunitário aparece associado à pobreza, à população de comunidades economicamente desfavorecidas, a contextos populares:

O que é por exemplo, o comunitário? A gente pensa logo numa coisa mais pobre... mais difícil, atinge logo aquela coisa mais popular... (ANGÉLICA TARSO apud SÁ BARRETO 2006: 231).

O que seria esse jornal comunitário? Seria um jornal que atende às pessoas que são desfavorecidas do ponto de vista de ter uma assistência da impressa, vamos dizer assim... (MÔNICA SILVEIRA apud SÁ BARRETO 2006: 231).

Dessa compreensão deriva uma posição de protagonista que o telejornalismo comunitário assume, chegando a se considerar porta-voz das populações das comunidades de contexto popular:

Ele é um telejornal que está mais próximo, a princípio, da população, dos problemas locais de determinadas comunidades, desenvolve alguns projetos como o "bairro que eu quero", que a população vota na urna: 'quais são os principais problemas do trânsito?'... aí vão lá... e dizem qual é. Acaba sendo aquela coisa de porta-voz da população. (JULIANO \MENDONÇA DA SILVA apud SÁ BARRETO 2006: 229).

É muito gratificante, quando a gente recebe o retorno das comunidades, principalmente as mais carentes, em função de determinadas conquistas que foram obtidas a partir de matérias que foram feitas... Então eu acho que nesse ponto a gente cumpre o nosso papel. (BIL ANTERO apud SÁ BARRETO 2006: 228).

E incorporando a posição de tutela dessas comunidades:

\footnotetext{
${ }^{2}$ SÁ BARRETO, Carmem Virgínia Montenegro. Comunidades Midiáticas e Culturas: as interrelações dialógicas na produção dos telejornais da Globo NETV E Jornal do Almoço.São Leopoldo: 2006. Tese (Doutorado em Ciências da Comunicação). Universidade Do Vale dos Sinos. RS.
} 
Um jornal comunitário é o que você pode denunciar e de resposta para a comunidade, por exemplo... a gente agora está com a série, 'o bairro que eu quero' mostra o problema, a comunidade diz o que acha que deveria ser o melhor serviço, o que melhoraria o bairro, para a gente cobrar da prefeitura aquela resposta, não é? A gente fica monitorando o que foi prometido, por exemplo, por meio de uma "sonora" do secretário de obras dizendo que 'aquele buraco ali em quinze dias a gente resolve... , Então, a gente mostra e daqui a quinze dias a gente vai, bota no ar, diz assim: 'olha, ele prometeu, mas está aqui... a obra está inacabada, ele ainda não terminou...' Aí a gente vai e pergunta por que? 'Ah! Eu disse mas teve um problema aqui, aqui...' então daqui a quanto tempo vai ser resolvido isso? 'Acho que mais uma semana...' Daqui a uma semana a gente está lá de volta. (HELOÍSA MARTMANN apud SÁ BARRETO 2006: 229).

A Rede Globo produziu uma série de programas jornalísticos voltados à abordagem de problemas e acontecimentos em contextos de comunidades populares, urbanas e rurais. Abrigado no sugestivo título de "Vida Real" o noticiário utiliza a dinâmica do jornalismo de televisão com um apresentador âncora que, no caso, tem a função de preparar o clima para a denúncia, que é o assunto da reportagem, evoluindo da indignação, frente ao fato reportado, às estratégias utilizadas pelo telejornal, com vistas à solução do problema. Na sequência, um repórter fala da comunidade, cenário do acontecimento, e em meio a população de contexto popular, emite um discurso que o faz evoluir de repórter narrador/intérprete do acontecimento à condição de mediador da população.

O protagonismo de repórter evolui para uma ação de tutela, na medida em que na sequência a reportagem avança para a busca de solução para o problema. É o que ficou evidenciado na análise de dois programas da série Vida Real, o "Há vida sem certidão" e "A dignidade mora ao lado" exibidos pela Rede Globo de Televisão, nos dias 11 de outubro e 11 de dezembro de 2009, respectivamente.

\subsection{Protagonismo: o clima de emoção}

A reportagem Há vida sem certidão, veiculada pela Rede Globo no dia 11 de outubro de 2009, inicia com a fala do apresentador que prepara a audiência pra se indignar diante de uma revelação/denúncia que constituirá o tema da reportagem. De pé no estúdio, com voz forte e pausada, ele inicia a narrativa:

Todo mundo quando nasce recebe um nome, uma identificação para toda vida. Esse nome se torna oficial na nossa certidão de nascimento. O documento que garante a cidadania e os nossos direitos. 
Mídias e culturas populares contemporâneas: mediação e tutela

de Maria Salett Tauk Santos

Na sequência, entra uma voz feminina, de uma apresentadora, que, ainda do estúdio, e com voz emocionada completa a narrativa do drama:

Agora, imagine o constrangimento que passa uma menina registrada com o nome de menino. Ela pode ficar sem escola, sem atendimento médico, sem respeito...

\subsection{Protagonismo: firmando o contrato com o popular}

Em seguida entra o repórter que, no cenário do acontecimento inicia a ação de protagonista em relação ao fato:

E a equipe do Vida Real encontrou uma família que sofre esse drama... Nós descobrimos essa história revoltante, por acaso. Como pode uma menina passar tanto tempo para trocar o nome no cartório? Vejam o que aconteceu e como vai terminar essa história.

\subsection{A Tutela}

Após entrevistar a mãe da menina, vítima de identidade trocada, que revelou ter tido ao Fórum da sua cidade inúmeras vezes para corrigir o nome da filha, sem sucesso, o repórter acompanha a mulher ao Fórum. De lá a mulher procura a secretária do Fórum, volta e fala ao repórter, no ar:

Ela disse que eu tenho que procurar um advogado de confiança ou a Defensoria Pública.

O repórter vai falar com a juíza de plantão no Fórum, em off. Na sequência aparece a juíza que fala: "o processo civil vai ser resolvido agora".

Entra o repórter enfatizando a vitória conquistada graças ao poder de sua tutela:

[...] A menina foi registrada em 2001. Hoje... em três horas conseguimos resolver um problema que não foi resolvido em oito anos.

A reportagem A dignidade mora ao lado da série Vida Real, que foi ao ar pela Rede Globo de Televisão no dia 11 de dezembro de 2009, segue a mesma lógica sequencial da reportagem anterior de motivar a audiência, por meio da indignação da 
Mídias e culturas populares contemporâneas: mediação e tutela

de Maria Salett Tauk Santos

equipe de produção e do repórter, do protagonismo dos repórteres apresentadores; e da tutela da mídia em relação às pessoas que vivem em comunidades populares.

A dignidade mora ao lado trata de 47 famílias que tendo perdido as suas casas, vítimas de enchentes e desabamentos em Pernambuco, invadiram casas de um conjunto popular que estavam sendo construídos para população de desabrigados. Essas famílias foram despejadas dessas casas e levadas para um galpão, onde passaram a viver em situação muito precária.

Em frente ao galpão, onde vivem atualmente as famílias, o repórter fala:

Depois que foram expulsos e trazidos para o galpão. Detalhe: elas foram levadas para um galpão onde só tem um banheiro para as 47 famílias.

E arremata num protagonismo emocionado:

Difícil não ficar emocionado e ao mesmo tempo revoltado com essa situação.... Elas estão lá dentro, mas a dignidade ficou do lado de fora.

A narrativa prossegue entre imagens e depoimentos sobre a penúria dos moradores do galpão e em seguida avança para a sequência de tutela da mídia, expressa nas cenas seguintes. Ocasião em que a reportagem procura o diretor presidente da Companhia Estadual de Habitação e Obras-CEHAB, responsável pela construção das casas para aquela população, e o interpela:

A gente entende que casa não se constrói da noite para o dia. Mas o que é difícil entender é porque colocaram as pessoas neste galpão?

O governo prometeu entregar essas casas no carnaval, mas nove meses se passaram e nada...

Para em seguida pressionar a autoridade, falando em nome da população, exigindo providências:

Vou entregar um calendário para o senhor. Segure. Marque aqui a data para entrega das casas...

Mas até lá, a gente quer saber o que será feito com essas famílias...

E arremata a mediação tuteladora:

... A gente vai acompanhar essa promessa neste galpão, em Vitória de Santo Antão. 


\section{CONSIDERAÇÕES FINAIS}

A evidência da ação tuteladora da mídia massiva frente às culturas populares coloca essas mídias num certo descompasso frente ao tempo contemporâneo e frente às novas sensibilidades e às novas formas da ação política erigida por meio das mídias sociais. No novo paradigma em gestação, o da cibercultura, as culturas populares, mediatizadas ou não, produzem mais do que sentidos, produzem conteúdos. A consequência disso é que mudam também as bases do contrato de comunicação que se estabelece entre a mídia e as culturas populares, como bem adverte Garcia Canclini: “para millones el problema no es mantener 'campos sociales alternos', sino ser incluidos, llegar a conectarse, sin que se atropelle su diferencia ni se los condene a la desigualdad. En suma, ser ciudadanos en sentido intercultural”. (CANCLINI 2008: 53)

A conexão torna-se, portanto, a regra para existência simbólica e material das culturas populares contemporâneas no cenário da construção da cidadania, não podendo as diferenças ceder lugar às desigualdades. Neste processo, a importância dos produtos culturais e da mídia nas realidades locais, como assinala Martin-Barbero (2003) dependem menos da quantidade e diversidade de informação circulante do que da capacidade de mobilização que eles geram.

\section{REFERÊNCIAS BIBLIOGRÁFICAS}

ESCOSTEGUY, Ana Carolina D. Cartografias dos estudos culturais - uma versão latino-americana. Belo Horizonte, Autêntica, 2001.

GARCÍA CANCLINI, Néstor . Diferentes, desiguales y desconectados: mapas de la interculturalidad. Barcelona (Espanha): Gedisa Editorial, 2008.

GARCÍA CANCLINI, Néstor. As Culturas populares no capitalismo. São Paulo, Brasiliense, 1983.

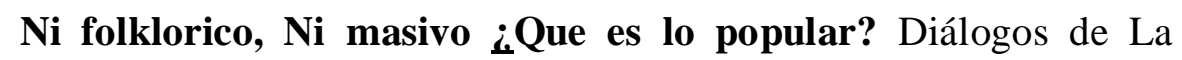
comunicación, Lima: FELAFACS, Junho de 1987, n. 17.

MORIN, Edgar. Ciência com Consciência. $2^{\mathrm{a}}$ ed. Rio de Janeiro: Bertrand, Brasil, 1998. 
MARTIN-BARBERO, Jesús. Globalização comunicacional e transformação cultural. In: MORAES, Dênis (org). Por uma outra comunicação: mídia, mundialização cultural e poder. Rio de Janeiro: Editora Record, 2003: 57-86.

MARTIN-BARBERO, Jesus. Pistas para entre-ver meios e mediações. Prefácio à $5^{\text {a }}$ edição castelhana De los médios a las mediaciones. Tradução de Maria Immacolata Vassallo de Lopes. BOGOTÁ, 1998.

A Mudança na percepção da juventude: sociabilidades, tecnicidades e subjetividades entre os jovens. In: Culturas juvenis no século XXI. (Organização: Silvia H. S. Borelli e João Freire Filho). São Paulo, Educ, 2008.

OROZCO GOMEZ, Guilermo. La investigacion en comunicación desde la perspectiva cualitativa. Mexico, INDEC, 1997.

SÁ BARRETO, Carmem Virgínia Montenegro. Comunidades Midiáticas e Culturas: as interrelações dialógicas na produção dos telejornais da Globo NETV E Jornal do Almoço.São Leopoldo: 2006. Tese (Doutorado em Ciências da Comunicação). Universidade Do Vale dos Sinos. RS.

TAUK SANTOS, Maria Salett. Inclusão digital, inclusão social?. In: TAUK SANTOS, Maria Salett (org). Inclusão digital, inclusão social? Usos das tecnologias da informação e comunicação nas culturas populares. Recife: Bagaço, 2009: 21-38.

TAUK SANTOS, Maria Salett; LIMA, Conceição Maria Dias de. Desafios cooperativos e estratégias de comunicação das incubadoras tecnológicas de cooperativas populares. In: UNIRCOOP: Volume 4, Número 1. 2006: 128-147.

TAUK SANTOS, M. Salett; NASCIMENTO, Marta R. Desvendando o mapa noturno: análise da perspectiva das mediações nos estudos de recepção IN: Recepção mediática e espaço público: novos olhares. Organização Mauro Wilton de Souza. São Paulo, Paulinas, 2006: 105-117.

TAUK SANTOS, Maria Salett. O consumo de bens culturais nas culturas populares: identidade reconvertida ou diversidade refuncionalizada? In Comunicação e Multiculturalismo (Organização: Cicília K. Peruzzo e J. B. Pinho). São Paulo, Intercom; Manaus: Universidade do Amazonas, 2001: 253-275. 
Mídias e culturas populares contemporâneas: mediação e tutela

TAUK SANTOS, Maria Salett. Quando a violência faz parte do contrato: estudo de recepção da Folha de Pernambuco. Anais do XXII Congresso Intercom; Manaus. AM, 5 a 6 de setembro de 2000.

VERÓN, E. L'analyse du contrat de lecture: pour une nouvelle méthode pour les études de positionement de supports press. In: Les médias, expériences, recherches actuelles, aplications. Paris, IREP, 1983.

VIDA REAL. A dignidade mora ao lado. Repórter Bruno Fontes. Recife: Rede Globo Nordeste, 11 de dezembro de 2009. Programa NE TV, $1^{\text {a }}$ ed.

VIDA REAL. Há vida sem certidão. Repórter Bruno Fontes. Recife: Rede Globo Nordeste, 11 de outubro de 2009. NE TV, $1^{\text {a }}$ ed.

Artigo recebido: 15/05/2012

Artigo aprovado: 30/05/2012 